\title{
Correction to: An Interprofessional Framework for Telebehavioral Health Competencies
}

\author{
Marlene M. Maheu ${ }^{1} \cdot$ Kenneth P. Drude ${ }^{2} \cdot$ Katherine M. Hertlein ${ }^{3} \cdot$ Ruth Lipschutz $^{4} \cdot$ Karen Wall $^{5} \cdot$ Donald M. Hilty $^{6}$
}

Published online: 26 February 2018

(C) Springer International Publishing AG, part of Springer Nature 2018

\section{Correction to: Journal of Technology in Behavioral Science}

(2017) 2:190-210

https://doi.org/10.1007/s41347-017-0038-y

The ESM should have been labeled Appendix Table 5 Interprofessional Framework for Telebehavioral Health Competencies

The online version of the original article can be found at https://doi.org/ 10.1007/s41347-017-0038-y

Marlene M. Maheu

mmaheu@telehealth.org

Kenneth P. Drude

kdrude@yahoo.com

Katherine M. Hertlein

katherine.hertlein@unlv.edu

Ruth Lipschutz

ruth.al@comcast.net

Karen Wall

logos68540@gmail.com

Donald M. Hilty

donh032612@gmail.com
1 Telebehavioral Health Institute, Inc., San Diego, CA, USA

2 Private Practice, Dayton, OH, USA

3 Couple and Family Therapy Program, School of Medicine, University of Nevada, Las Vegas, Las Vegas, NV, USA

4 University of Illinois at Chicago \& Institute for Family Studies at Northwestern University, Chicago, IL, USA

5 VA Palo Alto HCS-Menlo Park Division, Menlo Park, CA, USA

6 UC Davis Department of Psychiatry \& Behavioral Sciences, Sacramento, CA, USA 